\title{
Editorial Vol 18. N. 3 - Postcolonial and Intersectional studies. Multidimensional approaches and challenges for black women in the Americas
}

AABECAN tem satisfação de apresentar o volume 18, número 3 ( $30^{\circ}$ fascículo) da Interfaces Brasil/Canadá, Revista Brasileira de Estudos Canadenses. A edição tem sido viabilizada por meio de uma parceria com o Programa de Pós-Graduação em História da Universidade Federal de Pelotas (UFPel), com o Centro de Artes da Universidade Estadual de Santa Catarina (UDESC) e com o Núcleo de Estudos das Diversidades, Intolerâncias e Conflitos, da Universidade de São Paulo (USP).

O número que se apresenta aos leitores é dedicado ao dossiê Postcolonial and Intersectional studies. Multidimensional approaches and challenges for black women in the Americas, organizado pela professora Gislene Aparecida dos Santos, da Universidade de São Paulo, auxiliada por Camila Tavares de Moura Brasil Matos e Eloya Porto da Rocha, que comentarão a proposta com mais detalhes a seguir.

$\mathrm{Na}$ seção de fluxo contínuo Seção Paisagens, Patrimônios, Legitimidades e Educação nas Américas, contamos com o artigo Canadian and Brazilian research on L2 production and the Output Hypothesis: seeking for a psycholinguistic rationale for the use of translation in L2 learning, de autoria de Maria da Glória Guará-Tavares e Antonia de Jesus Sales, que busca uma base psicolinguística para o uso da tradução pedagógica na aprendizagem de uma segunda língua.

Na seção de resenhas e entrevistas, Gunter Axt entrevista a célebre historiadora estadunidense Camille Paglia, abordando temas diversos, como a tradição intelectual norte-americana, pós-estruturalismo, politicamente correto, gênero e educação nos dias atuais. Oscar Berg entrevista Zilá Bernd, conhecida especialista dedicada aos estudos canadenses no Brasil, conversando sobre sua trajetória acadêmica e sobre francofonia. Eloína Prati dos Santos nos oferece uma resenha da mostra cinematográfica Tela Indigena, realizada no Cine Capítólio em Porto Alegre, em setembro de 2018. Núbia Hanciau resenha o livro de Zila Bernd A persistência da memória em textos literários. Romances da anterioridade e seus modos de transmissão intergeracional. Finalmente, 
Zila Bernd resenha a obra de Rita Olivieri-Godet e Rachel Bouvet, Geópoétique des confins, recentemente publicada em Rennes, na França.

Gunter Axt, editor-chefe

Eloína Prati dos Santos, editora assistente

Fábio Vergara Cerqueira, editor assistente

Monique Vandresen, editora especial de editoração e de impressão

\section{Estudos pós-coloniais e interseccionais. Abordagens e desafios multidimensionais para mulheres negras nas Américas}

Ao realizarmos a proposta para o dossiê Estudos pós-coloniais e interseccionais. Abordagens multidimensionais e desafios para mulheres negras nas Américas queríamos divulgar pesquisas focadas em desafios para mulheres negras que vivem e atuam nesta parte do globo. Nosso intento era buscar e compreender as estratégias criadas para enfrentar discriminações baseadas em raça, mas, também, em gênero, classe, cor e etnia, considerando a interseccionalidade como elemento essencial, conforme o proposto por Kimberlé Crenshaw. Essa proposta está alinhada com o projeto que desenvolvemos no período, financiado pela CAPES (Coordenação de Aperfeiçoamento de Pessoal de Nível Superior - Código de Financiamento 001), e cujo intuito é exatamente esse: discutir estratégias construídas por mulheres negras para lidar com as discriminações.

Propusemos alguns questionamentos capazes de nortear a discussão: quais seriam as estratégias? Como são desenvolvidas? É possível afirmar que são as mesmas em diferentes partes das Américas? Sistemas de poder interligados baseados no colonialismo, o imperialismo, sexismo, classismo, racismo e patriarcado têm o mesmo modo de aparecer em diferentes regiões? E mais, como construir uma agenda para enfrentar a opressão multidimensional e interseccional contra as mulheres negras nas Américas? Seria possível construir estratégias de descolonização além das fronteiras? 
Os autores e autoras dos artigos que apresentamos enfrentaram essas questões. Podemos dizer que estamos muito felizes em divulgar os trabalhos rigorosos que foram feitos e estão sendo feitos para contribuir com a reflexão sobre o tema.

Os artigos que compõem esse dossiê revelam valiosas pesquisas oriundas de diferentes áreas do conhecimento. No campo da educação, há a sugestão de um caminho para a emancipação e enfrentamento de discriminações sugerido por Rosangela Malachias. No artigo Mulheres líderes em educação. Da baixada fluminense para o Mundo, Malachias apresenta a sua atuação como docente na Escola de Educação da Universidade Estadual do Rio de Janeiro - UERJ, contextualizando o esforço em empregar um projeto e engajar os alunos em busca de um olhar interseccional para a participação da 6th WLE ConferenceBrazil. Destaca, ainda, sua ação como mulher negra e a necessidade de pesquisas, dentro das universidades, que abordem a representatividade deste grupo, sem estereótipos, e não só, que coloquem em destaque experiências que com enfoque interseccionais voltadas para raça, gênero, cor, classe.

O destaque para a representatividade de mulheres negras nos espaços acadêmicos também é o pano de fundo do artigo Mulheres negras acadêmicas: preconceito, discriminação e estratégias de enfrentamento em uma universidade pública do Brasil, escrito Bruna Lanzoni Munoz, Gisela Lays dos Santos Oliveira e Alessandro de Oliveira dos Santos. Este trabalho apresenta resultados de um qualitativo sobre experiências de preconceito contra mulheres negras na Universidade de São Paulo (USP) e como elas atuaram para enfrentar as discriminações sofridas. Os autores realizaram entrevistas com 15 mulheres negras evidenciando três eixos principais: o que é ser mulher negra? Quais experiências de preconceito sofrem ou sofreram dentro do espaço universitário? E quais são as estratégias de enfrentamento empregadas? Temos relatos muito importantes para avançar no debate do tema principalmente revelando a existência do racismo estrutural e como combatê-lo.

Também buscando entender como raça e gênero devem ser abordados em pesquisas com o objetivo de discutir sobre discriminações e racismo, Gislene Aparecida dos Santos traz importantes contribuições em Raça e Gênero: contribuições para pesquisas nas ciências sociais e jurídicas, (texto apresentado nas versões em português 
e inglês) e, também, no texto escrito em parceria com Camila Tavares de Moura Brasil Matos, intitulado Estratégias construidas por mulheres negras para o enfrentamento das discriminações por raça e gênero no Brasil e no Canadá: desafios de um projeto de pesquisa. A pesquisa conduzida por Gislene Santos busca apresentar quais são as múltiplas dimensões que as categorias raça e gênero podem assumir quando se discutem desigualdades. Utilizando processos do Tribunal de Justiça do Estado de São Paulo como ponto de partida, a autora nos apresenta 39 casos como amostra para discutir quais desafios e sugestões para uma agenda de pesquisa em raça e gênero com especial destaque para as múltiplas dimensões que o estudo dessas categorias implica. Nesse mesmo sentido, o segundo artigo, feito em parceria com sua orientanda, Camila Matos, expõe projetos que abordam o entrecruzamento de gênero e raça, fazendo um paralelo com a forma como autores canadenses abordam o mesmo tema. Como ponto de partida, a compreensão dos estudos pós-coloniais e do feminismo negro se mostrou imperioso na condução e avanço nas pesquisas no tema.

Dentro do eixo de pesquisas em direitos humanos, prosseguimos com o trabalho Estratégias de saúde realizadas por/para mulheres negras nas Américas: revisão de escopo realizado por Clélia R. S. Prestes, Felipe L. Fachim e Vera S. F. Paiva, cujo foco é demonstrar quais as estratégias de promoção de saúde voltadas para a resiliência, agência e empoderamento de mulheres negras. A pesquisa, conduzida por meio de revisão de literatura científica, se focou nos conceitos de interseccionalidade e o bem-viver tentando compreender o que já foi produzido, no campo científico, em torno do tema. Os autores destacam que, embora tenham identificado um pouco mais de 800 artigos, apenas 12 se focavam especificamente naquelas estratégias, sem trazer reflexões para as causas e problemas de saúde que afetam mulheres negras, algo que o artigo produzido por eles busca discutir. Além disso, destacam a importância de que mulheres negras sejam atuantes e consideradas nas pesquisas na área da saúde.

Em meio à era digital e de ativismo nas redes socias, destacamos Afro-Brazilian women YouTubers. Black Feminism in Digital Social Justice Activism, escrito por Gladys Mitchell-Walthour, cuja pesquisa coloca em foco como jovens negras youtubers atuam enfrentando o racismo, sexismo e colorismo, por meio do feminismo negro. A autora nos 
explica que estas jovens fazem parte de um novo movimento ativista que atua nas redes sociais, sendo a principal ferramenta para disseminação de conteúdo, o Youtube. Gladys Mitchell-Walthour analisou 100 vídeos para compreender os assuntos abordados por ativistas negras. Sua pesquisa aponta que um dos principais temas abordados nos canais são o empoderamento de meninas e mulheres negras por meio da aceitação da beleza e da identidade negra que elas expõem como forma de resistência ao estereótipo negativo sobre o que é ser mulher negra.

Outro modo de fortalecimento (empowerment) é discutido no artigo Jenyffer Nascimento's Epic Poetry of Black Female Empowerment, de Sarah Ohmer. A autora analisa a obra de Jennyffer Nascimento, Terra Fértil, na qual focaliza a perspectiva poética de uma mulher negra sobre diferentes aspectos literários que afetam ou influenciam a vida de outras mulheres, na periferia de São Paulo. A autora analisa cada poema compreendendo que a obra da Nascimento é na verdade, um manual de sobrevivência e resistência.

Sendo assim, no dossiê, reunimos e apresentamos trabalhos acadêmicos com foco em discutir situações vivenciadas por mulheres negras, trazendo distintas estratégias de enfrentamento, mas, sobretudo, demonstramos como essas questões podem ser abordadas e discutidas no campo acadêmico/científico de maneira a podermos avançar nesta temática, em diferentes áreas de conhecimento.

Gislene Aparecida dos Santos, editora convidada Camila Tavares de Moura Brasil Matos, Eloya Porto da Rocha, assistentes 